\title{
Examining Liver Function in Adults with Diabetes in the United States
}

\author{
Prashant Sakharkar ${ }^{1}$ and Subrata Deb ${ }^{2}$ \\ ${ }^{1}$ Roosevelt University College of Pharmacy, Schaumburg, IL, USA; ${ }^{2}$ Department of Pharmaceutical Sciences, College of \\ Pharmacy, Larkin University, Miami, FL, USA
}

Corresponding Author: Subrata Deb, B.Pharm, PhD, Department of Pharmaceutical Sciences, College of Pharmacy, Larkin University; Miami, FL 33169, USA; TEL: (224)-310-7870; email: sdeb@alumni.ubc.ca

Received, March 26, 2021; Revised, June 10, 2921; Accepted, June 11, 2021; Published, June 16, 2021

\begin{abstract}
Purpose: Hyperglycemia is the hallmark of various types of diabetes and considered to be a risk factor for several chronic disorders including liver function. Though liver is a dynamic organ, incessant glucotoxicity can lead to altered liver function. The goals of the present study were to examine the association between diabetes with liver functions amongst adults in the United States. Methods: We analyzed 14,948 adults with diabetes in the National Health and Nutrition Examination Survey (NHANES) conducted from 2007 to 2016. Diabetes and prediabetes were defined in accordance with the American Diabetes Association 2021 guidelines. The association of demographic characteristics with glycemic levels was analyzed using the Chisquare test. A multivariate logistic regression model was constructed to evaluate the associations of glycemic levels with abnormal liver enzyme levels. Regression model was adjusted for age, sex, and ethnicity. The statistical analyses were performed using STATA ver. 14. A $p$ value of $\leq 0.05$ or $\leq 0.001$ was considered statistically significant. Results: A total of 14,948 adults (20 years and above) were included in this study. Sample mean age was $45.5 \pm 0.33$ yrs., $54 \%$ were female, $53 \%$ were non-Hispanic White, and $60 \%$ had some college or graduate level education. In the overall sample, $19 \%$ adults were diabetic and $34 \%$ were pre-diabetic. Pre-diabetic glycemic levels were associated over one and half times higher odds of ALT (OR: 1.45, 95\% CI: 1.31, 1.60, $p<0.001)$ and over 1.3 times of higher odds AST (OR: $1.30,95 \%$ CI: 1.14, 1.49, $p<0.001$ ). On the other hand, diabetic glycemic levels were associated with close to one and half times higher odds of ALT (OR: 1.37, 95\% CI: 1.18, $1.59, p<0.001)$ and AST (OR: 1.48, 95\% CI: 1.24, 1.76, $p<0.001)$. On regression analysis, after adjustment, prediabetic and diabetic status was associated with high ALT (OR: 1.21, 95\%CI: 1.11, 1.32, p<0.001), AST (OR: 1.14, 95\%CI: 1.04, 1.27, p<0.05), ALP (OR: 1.40, 95\%CI: 1.16, 1.68, p<0.001) and GGT (OR: 1.42, 95\%CI: 1.24, $1.63, \mathrm{p}<0.001)$. Conclusions: Our results indicated that diabetes is significantly associated with liver function. This observed association deserves further exploration to understand the longitudinal impact of diabetes on liver function.
\end{abstract}

\section{INTRODUCTION}

Hyperglycemia is the hallmark of various types of diabetes including Type 1, Type 2 and gestational diabetes mellitus. According to Centers for Disease Control and Prevention (CDC), approximately 30 million Americans have diabetes with $\sim 1.5$ million new diabetes cases diagnosed each year. A staggering 84 million Americans (>18 year) have prediabetes (1). Globally, 422 million individuals have diabetes with at least 3.7 million diabetesrelated reported deaths each year (2). It has been evidenced that hyperglycemia-associated change in underlying pathophysiology of vital organs typically leads to comorbidities including, but not limited to, cardiovascular disease, renal and endocrine cancer (3). The total costs of diabetes have been estimated to be $\$ 327$ billion with the notion that healthcare costs of people with diabetes are $>2$-fold more than the undiagnosed populations (4). Thus, in addition to the diabetes pathophysiology, it is imperative to understand the comorbidities that could be associated with elevated glucose levels.

Hyperglycemia is a pathophysiological condition where formation of glucose is much higher than its utilization as an "obligate fuel". The physiology of glucose homeostasis is complicated with involvement of several organs including brain, liver, pancreas, skeletal muscle and adipose tissues (5). Among these, liver is a pivotal site of glucose synthesis and storage. Fasting and postprandial glucose are the oldest diagnostic markers of hyperglycemia. However, glycated hemoglobin (HbA1c), which is generated following conjugation 
of glucose to a protein in RBC, has been increasingly used to understand the duration of elevated plasma glucose levels (6). Unlike the plasma glucose levels, the percentage of $\mathrm{HbA} 1 \mathrm{c}$ does not fluctuate dramatically and offers advantage in precisely understanding the glucose homeostasis. A multitude and complex array of factors have been ascribed to elevated glucose levels or increased $\mathrm{HbA} 1 \mathrm{c} \%$ including bodyweight, race/ethnicity, dietary habits, stress and endocrine disruption (7). Increased waist circumference and body mass index (BMI) are two very commonly observed non-glycemic parameters that appear along with elevated glucose levels (7).

Typically, the aspartate aminotransferases (AST) and alanine aminotransferases (ALT) enzymes, the biomarkers of hepatic stress or injury, are localized within the healthy hepatocytes but during hepatic necrosis or proliferation they are released in the serum (8). Along with aminotransferases, alkaline phosphatase (ALP) levels are also indicative of hepatocyte integrity. A healthy liver typically does not undergo frequent mitosis; however, liver injury from endogenous or xenobiotic substances triggers liver proliferation and potential increase in liver enzymes (9). In spite of a large number of people in the United States and globally exhibits elevated glucose levels, there have been limited information about the impact of hyperglycemia on hepatic function and integrity derived from large population based observational studies. The purpose of the present study was to examine the association between hyperglycemiarelated markers with liver enzyme functions amongst adults in the United States. The National Health and Nutrition Examination Survey (NHANES) database of non-institutional civilian population of the United States was explored to conduct the study. The outcomes of this retrospective work provide us with the evidence that elevated glucose levels for a prolong time have the potential to cause liver dysfunction.

\section{MATERIALS AND METHODS}

\section{Study Population}

We analyzed the sample of adults 20 years and older who participated in NHANES, an ongoing population-based statistical survey to estimate the health status of the noninstitutionalized civilian US population, based on interview, examination, and laboratory information from representative samples of US households. In-person interviews were conducted in sampled households, and subjects were invited to participate in medical examinations. Participants were selected using a stratified multistage probability design with oversampling of certain age and ethnic groups. Data were extracted by accessing the CDC website which hosts NHANES datasets. Relevant data files were downloaded as SAS transport files. Subsequently, SPSS ver. 27 (IBM Corp., Armonk, NY, USA) and STATA ver. 14 (STATACorp., College Station, TX, USA) were used to export, merge, manage, organize, and perform the statistical analyses. We extracted data on individuals who participated in NHANES from 2007 through 2016 into a combined dataset (NHANES 2007-2016) to increase sample size for greater estimator reliability (NHANES Analytic Guidelines) (10). Of total 51,694 participants on whom information gathered during a home interview, $48,710(94 \%)$ were also screened for laboratory data. We excluded individuals $(26,983)$ who either had hepatitis B surface antibody $(n=12,599)$, hepatitis B surface antigen (159), hepatitis D antibody (43) and hepatitis $\mathrm{C}$ confirmed antibody combined $(n=336)$, and hepatitis A antibody $(21,737)$ and hepatitis B core antibody $(n=2,071)$. We also excluded participants who self-reported of having liver condition on interview $(1,127)$ and with either missing HbA1C, AST, ALT, ALP, GGT and Total bilirubin levels $(n=19,795)$ leaving final adjusted sample of 14,948 participants of age 20 years or older for analyses. As defined in federal regulations, use and analysis of deidentified publicly available data does not constitute human subjects research and as such does not require IRB review. Hence, institutional Review Board (IRB) approval was not necessary nor sought for this research.

\section{Covariates}

Covariates included age, sex, ethnicity/race, education, income, poverty level, Body mass Index (BMI), Systolic Blood Pressure (SBP), Diastolic Blood Pressure (DBP), Fasting Plasma Glucose (FPG), Oral Glucose Tolerance Test (OGTT) and Glycosylated hemoglobin (HbA1C). Age, ethnicity/race, income, knowledge of having diabetes was self-reported by the participants.

\section{Study Definitions}

Diabetes was defined in accordance with the American Diabetes Association 2021 guidelines for the glycemic ranges (6). Individuals were considered diabetic, if they either had $\mathrm{HbA} 1 \mathrm{C}$ of $6.5 \%$ or higher; FPG $126 \mathrm{mg} / \mathrm{dl}$ or higher or OGTT of $200 \mathrm{mg} / \mathrm{dl}$ or higher or answered yes to the question "Doctor told 
you have diabetes" on the interview. Participants with FPG between $100-125 \mathrm{mg} / \mathrm{dl}$, OGTT between $140-199 \mathrm{mg} / \mathrm{dl}$ and $\mathrm{HbA} 1 \mathrm{C}$ between $5.7 \%-6.4 \%$ were considered prediabetic. Body mass index, a measure of obesity defined as weight in kilograms divided by height in meters squared, was categorized according to clinical guidelines set by the National Institute of Health (11).

\section{Statistical Analysis}

The statistical analyses for this study were performed using STATA ver. 14, a statistical software package that takes into account sample weighting and the complex, multistage probability sample design of NHANES (12). Demographic characteristics were compared by age, sex, race/ethnicity, education, and glycemic markers using the Chi-square test followed by post-hoc analyses with Bonferroni correction. Sampling weights were applied to take into account selection probabilities, oversampling, nonresponse, and differences between the sample and the US adolescent male population. We examined the association between glycemic levels and liver enzyme levels. A multivariate logistic regression model was constructed to evaluate the associations of glycemic levels with abnormal liver enzyme levels. There is no universal agreement about the target values for ALT and AST in published literature. In this study, we defined abnormal ALT and AST values as a range $(<20 \mathrm{mg} / \mathrm{dl}, 20-29 \mathrm{mg} / \mathrm{dl}, 30-$ $39 \mathrm{mg} / \mathrm{dl}$ and $\geq 40 \mathrm{mg} / \mathrm{dl}$ ) for total sample population. A threshold value of 120U/L and higher for ALP, $17 \mathrm{mmol} / \mathrm{dl}$ for total bilirubin, and AST/ALT ratio of 1 was used. We also used sex-based target values of $\operatorname{ALT}(\geq 30 \mathrm{U} / \mathrm{L}$ for male and $\geq 25 \mathrm{U} / \mathrm{L}$ for female) and AST ( $\geq 33 \mathrm{U} / \mathrm{L}$ for male and female both), and GGT ( $\geq 65 \mathrm{IU} / \mathrm{L}$ for male, $\geq 36 \mathrm{IU} / \mathrm{L}$ for female) to explore if this change in target values produces any difference in associations (13). These target values were chosen as it represents common institutional reference values and commonly used in the clinical practice. Similar target values have been used in both adolescent and adult epidemiological studies. Our regression model included age, sex, ethnicity/race, education, income, poverty level, BMI, SBP, DBP, FPG, OGTT and HbA1C as covariates. These covariates were chosen based on the prior evidence from the literature and based on biological plausibility. We used Hosmer-Lemeshow test to evaluate the goodness of fit and adherence to the model assumptions. Taylor series linearization was used for variance estimation. A $p$ value of $\leq 0.05$ or $\leq 0.001$ was considered statistically and highly statistically significant, respectively.

\section{RESULTS}

\section{Study Participants}

Table 1 presents the demographic characteristics of individuals with non-diabetic, prediabetic and diabetic status. A total of 14,948 adults (20 years and above) were included in this study. Sample mean age was $45.5 \pm 0.33$ yrs. and majority (52\%) individuals were between age 20 and 44 years, $54 \%$ were female, $53 \%$ were non-Hispanic White, and $60 \%$ had some college or graduate level education. A total of $60 \%$ individuals had family income of less than $\$ 55,000$, $67 \%$ were overweight and obese, $73 \%$ had hypertension and $84 \%$ were taking prescription medication for hypertension. Forty seven percent individuals were taking diabetic pills to lower their blood sugar and $43 \%$ were engaged in moderate recreational activities. In overall sample, $19 \%$ adults were diabetic and had $\mathrm{HbA} 1 \mathrm{C}$ levels $6.5 \%$ and higher, FPG level of $126 \mathrm{mg} / \mathrm{dL}$ and greater, OGTT level of $200 \mathrm{mg} / \mathrm{dL}$ and higher according to the ADA guidelines. Thirty four percent participants were prediabetic and had HbA1C levels between 5.7 and $6.5 \%$, FPG level between $100 \mathrm{mg} / \mathrm{dL}$ and $125 \mathrm{mg} / \mathrm{dL}$ and OGTT level between $140 \mathrm{mg} / \mathrm{dL}$ and $199 \mathrm{mg} / \mathrm{dL}$ (Table 1).

\section{Association of Participants Characteristics and Glycemic Levels}

We examined the association of demographic characteristics with glycemic levels using the Chisquare test. Age, sex, and race/ethnicity, education, family income showed significant association with glycemic levels (pre-diabetic and diabetic). Post hoc analyses showed that age of forty-five years and above, female sex and non-Hispanic white and black ethnicity were significantly associated with high glycemic levels. Education higher than some college degree and family income less than $\$ 25,000$ was also significantly associated with high glycemic levels. Similarly, obesity, presence of hypertension, taking medication for blood pressure and diabetes and doing moderate recreational activities were significantly associated with high glycemic levels (pre-diabetic and diabetic) (Table 1). Adults had mean BMI of $31.6 \mathrm{~kg} / \mathrm{m} 2$ and waist circumference of $107.2 \mathrm{~cm}$ in individuals with diabetes, well in the abnormal range with the target values for BMI, and waist 
Table 1: Demographic characteristics and laboratory data of NHANES participants (2007-2016).

\begin{tabular}{|c|c|c|c|c|c|}
\hline & $\begin{array}{l}\text { Total Sample } \\
\mathrm{N}=14,948\end{array}$ & $\begin{array}{l}\text { Non-diabetic } \\
n=6,965\end{array}$ & $\begin{array}{l}\text { Pre-diabetic } \\
\mathrm{n}=5,128\end{array}$ & $\begin{array}{r}\text { Diabetic } \\
n=2,855\end{array}$ & p-value \\
\hline Age (yrs.) (Mean \pm SE) & $45.5 \pm 0.33$ & $38.7 \pm 0.37$ & $51.1 \pm 0.38$ & $61.1 \pm 0.40$ & $<0.001 * *$ \\
\hline \multicolumn{6}{|l|}{ Age (yrs.) } \\
\hline $20-44$ & $6447(51.9)$ & $4545(69.0)$ & $1606(37.7)$ & $296(13.7)$ & \multirow[t]{3}{*}{$<0.001 * *$} \\
\hline $45-64$ & $4771(29.2)$ & $1593(22.0)$ & $1997(36.7)$ & $1181(41.7)$ & \\
\hline$>=65$ & $3730(18.9)$ & $827(8.0)$ & $1525(25.6)$ & $1378(44.6)$ & \\
\hline \multicolumn{6}{|l|}{ Sex } \\
\hline Male & $7037(45.8)$ & $3007(43.1)$ & $2607(50.5)$ & $1423(46.2)$ & \multirow[t]{2}{*}{$<0.001 *$} \\
\hline Female & $7911(54.2)$ & $3958(56.9)$ & $2521(49.5)$ & $1432(53.8)$ & \\
\hline \multicolumn{6}{|l|}{ Marital Status } \\
\hline Single & $2821(21.5)$ & $1900(28.1)$ & $681(14.8)$ & $240(9.6)$ & \multirow[t]{3}{*}{$<0.001 * *$} \\
\hline Married & $7664(52.6)$ & $3276(49.2)$ & $2792(56.5)$ & $1596(57.0)$ & \\
\hline Other & 4457 (25.9) & $1785(22.7)$ & $1655(28.7)$ & $1017(33.4)$ & \\
\hline \multicolumn{6}{|l|}{ Race/Ethnicity } \\
\hline Mexican American & $3301(14.2)$ & $1392(12.7)^{\mathrm{a}}$ & $1174(15.5)$ & $735(17.1)$ & \multirow[t]{5}{*}{$<0.05 *$} \\
\hline Other Hispanic & $2106(8.7)^{a}$ & $933(8.4)^{\mathrm{a}}$ & $748(8.8)$ & $425(9.1)^{\mathrm{a}}$ & \\
\hline Non-Hispanic White & $4324(53.3)$ & $2326(57.7)$ & $1360(49.7)$ & $638(43.9)$ & \\
\hline Non-Hispanic black & $3020(12.3)$ & $1210(10.2)$ & $1106(13.9)$ & $704(17.6)$ & \\
\hline Other & $2197(11.5)$ & $1104(11.0)^{\mathrm{a}}$ & $740(12.1)$ & $353(12.3)$ & \\
\hline \multicolumn{6}{|l|}{ Education } \\
\hline$<9^{\text {th }}$ Grade & $2472(9.8)$ & $741(6.3)$ & $964(11.9)$ & $767(19.2)$ & \multirow[t]{5}{*}{$<0.001 * *$} \\
\hline $9-11^{\text {th }}$ Grade & $2300(12.1)$ & $920(9.8)^{\mathrm{a}}$ & $841(13.9)^{\mathrm{a}}$ & $539(17.6)$ & \\
\hline High School/GED & $3080(19.8)$ & $1390(18.1)^{\mathrm{a}}$ & $1062(21.2)^{\mathrm{a}}$ & $628(23.0)^{\mathrm{a}}$ & \\
\hline Some College or AA degree & $3861(29.8)$ & $2062(32.4)$ & $1234(27.3)$ & $565(24.7)$ & \\
\hline College Graduate or above & $3217(28.6)$ & $1849(33.4)$ & $1019(25.7)$ & $349(15.5)$ & \\
\hline \multicolumn{6}{|l|}{ Family Income } \\
\hline$<\$ 25,000$ & $5080(28.4)$ & $2159(26.0)$ & $1771(29.3)$ & $1150(36.3)$ & \multirow[t]{4}{*}{$<0.001 * *$} \\
\hline$\$ 25,000-\$ 54,999$ & $4690(31.6)$ & $2158(30.0)^{a}$ & $1609(32.6)^{a}$ & $923(36.2)^{a}$ & \\
\hline$\$ 55,000-\$ 99,999$ & $2445(20.1)$ & $1194(20.6)^{a}$ & $829(20.0)^{\mathrm{a}}$ & $422(18.1)^{a}$ & \\
\hline$>\$ 100,000$ & $1882(19.9)$ & $1090(23.4)$ & $605(18.1)^{\mathrm{a}}$ & $187(9.4)$ & \\
\hline \multicolumn{6}{|c|}{ Ratio of Family Income to Poverty } \\
\hline$<1.35$ & $5110(28.6)$ & $2319(27.5)$ & $1710(28.2)^{a}$ & $1081(34.5)$ & \multirow[t]{4}{*}{$<0.001 * *$} \\
\hline $1.35-1.84$ & $1717(10.8)$ & $745(9.7)$ & $620(11.6)^{\mathrm{a}}$ & $352(13.5)^{a}$ & \\
\hline $1.85-2.99$ & $2401(17.9)$ & $1092(16.7)^{a}$ & $823(18.9)^{\mathrm{a}}$ & $486(20.6)^{a}$ & \\
\hline$>=3.00$ & $4219(42.7)$ & $2187(46.2)$ & $1432(41.3)^{\mathrm{a}}$ & $600(31.4)$ & \\
\hline \multicolumn{6}{|l|}{ BMI $\left(\mathrm{kg} / \mathrm{m}^{2}\right)$} \\
\hline Underweight & $240(1.8)$ & $170(2.5)$ & $56(1.0)$ & $14(0.5)$ & \multirow[t]{4}{*}{$<0.001 * *$} \\
\hline Normal & $4302(31.5)$ & $2681(40.2)$ & $1188(23.4)$ & $433(14.4)$ & \\
\hline Overweight & $5022(33.1)$ & $2275(32.5)^{\mathrm{a}}$ & $1855(35.4)$ & $892(30.2)^{a}$ & \\
\hline Obese & $5210(33.6)$ & $1776(24.8)$ & $1983(40.2)$ & $1451(54.9)$ & \\
\hline \multicolumn{6}{|l|}{ SBP } \\
\hline$<130 \mathrm{mmHg}$ & $9904(75.1)$ & $5389(83.6)$ & $3154(69.3)$ & $1361(53.8)$ & \multirow[t]{2}{*}{$<0.001 * *$} \\
\hline$>=130 \mathrm{mmHg}$ & 4475 (24.9) & $1306(16.4)$ & $1778(30.7)$ & $1391(46.2)$ & \\
\hline \multicolumn{6}{|l|}{ DBP } \\
\hline$<85 \mathrm{mmHg}$ & $13188(92.7)$ & $6262(94.2)$ & $4416(90.8)$ & $2510(90.9)$ & \multirow[t]{2}{*}{$<0.001 * *$} \\
\hline$>=85 \mathrm{mmHg}$ & $1191(7.3)$ & $433(5.8)$ & $516(9.2)$ & $242(9.1) \mathrm{a}$ & \\
\hline Hypertension (130/85mmH & & & & & \\
\hline Yes & $9634(73.2)$ & $5260(81.7)$ & $3046(67.0)$ & $1328(52.4)$ & $<0.001 * *$ \\
\hline No & $4745(26.8)$ & $1435(18.3)$ & $1886(33.0)$ & $1424(47.6)$ & \\
\hline Take diabetic pills to lower & & & & & \\
\hline Yes & $1563(46.7)$ & $10(3.8)$ & $52(8.3)$ & $1501(67.5)$ & $<0.001 * *$ \\
\hline No & $1428(53.3)$ & $241(96.2)$ & $499(91.7)$ & $688(32.5)$ & \\
\hline
\end{tabular}

Table 1. continues... 


\begin{tabular}{|c|c|c|c|c|c|}
\hline & $\begin{array}{l}\text { Total Sample } \\
\mathrm{N}=\mathbf{1 4 , 9 4 8}\end{array}$ & $\begin{array}{l}\text { Non-diabetic } \\
n=6,965\end{array}$ & $\begin{array}{l}\text { Pre-diabetic } \\
n=5,128\end{array}$ & $\begin{array}{r}\text { Diabetic } \\
n=2,855\end{array}$ & p-value \\
\hline \multicolumn{6}{|l|}{ Taking prescription for hypertension } \\
\hline Yes & $4449(84.1)$ & $983(72.3)$ & $1736(85.8)^{a}$ & $1730(95.0)$ & $<0.001 * *$ \\
\hline No & $622(15.9)$ & $313(27.7)$ & $217(14.2)^{\mathrm{a}}$ & $92(5.0)$ & \\
\hline \multicolumn{6}{|l|}{ Moderate recreational activities } \\
\hline Yes & $5659(43.3)$ & $2933(47.5)$ & $1909(41.4)^{\mathrm{a}}$ & $817(30.1)$ & $<0.001 * *$ \\
\hline No & $9287(56.7)$ & $4032(52.5)$ & $3219(58.6)^{a}$ & $2036(69.9)$ & \\
\hline BMI $\left(\mathrm{kg} / \mathrm{m}^{2}\right)($ Mean \pm SE $)$ & $28.3 \pm 0.11$ & $26.8 \pm 0.12$ & $29.5 \pm 0.16$ & $31.6 \pm 0.19$ & $<0.001 * *$ \\
\hline Waist Circumference $(\mathrm{cm})(\mathrm{Mean} \pm \mathrm{SE})$ & $96.7 \pm 0.27$ & $92.3 \pm 0.30$ & $100.3 \pm 0.35$ & $107.2 \pm 0.41$ & $<0.001 * *$ \\
\hline FPG $(\mathrm{mg} / \mathrm{dl})(\mathrm{Mean} \pm \mathrm{SE})$ & $106.0 \pm 0.51$ & $91.2 \pm 0.14$ & $103.1 \pm 0.23$ & $149.3 \pm 2.3$ & $<0.001 * *$ \\
\hline OGTT $(\mathrm{mg} / \mathrm{dl})($ Mean \pm SE $)$ & $115.9 \pm 0.76$ & $92.5 \pm 0.63$ & $120.4 \pm 0.84$ & $227.7 \pm 4.2$ & $<0.001 * *$ \\
\hline HbA1C $(\%)($ Mean \pm SE $)$ & $5.6 \pm 0.01$ & $5.2 \pm 0.01$ & $5.7 \pm 0.01$ & $7.2 \pm 0.04$ & $<0.001 * *$ \\
\hline SBP $(\mathbf{m m H g})($ Mean \pm SE $)$ & $121.2 \pm 0.26$ & $117.0 \pm 0.26$ & $124.4 \pm 0.33$ & $131 \pm 0.55$ & $<0.001 * *$ \\
\hline DBP $(\mathrm{mmHg})($ Mean $\pm \mathrm{SE})$ & $69.3 \pm 0.24$ & $69.0 \pm 0.27$ & $70.4 \pm 0.30$ & $69.9 \pm 0.42$ & $<0.001 * *$ \\
\hline
\end{tabular}

Data were reported as n (\%) unless specified; BMI: Body Mass Index; SBP: Systolic blood pressure; DBP: Diastolic blood pressure; FPG: Fasting Plasma Glucose; OGTT: Oral Glucose Tolerance Test: HBA1C: Glycosylated hemoglobin. Significant at $* p<0.05$ and $* * p<0.001$.

circumference (Table 1). We also examined the association of BMI with liver enzymes. BMI was found significantly associated with liver enzymes ALT and AST, AST/ALT ratio, ALP, GGT and total bilirubin $(\mathrm{p}<0.001)$ (data not shown). Post hoc analyses showed overweight individuals (BMI $\geq 25$ ) were most likely to high liver enzyme levels.

\section{Association of Glycemic Levels with Abnormal Liver Enzymes}

We also examined the association of glycemic levels with liver enzymes. Glycemic levels were found significantly associated with liver enzymes ALT and AST, AST/ALT ratio, ALP, and total bilirubin (Table 2). Post hoc analysis showed diabetic glycemic levels were significantly associated with high AST $(\geq 33 \mathrm{U} / \mathrm{L})$ and ALP $((\geq 120 \mathrm{mg} / \mathrm{dL})$, whereas prediabetic glycemic levels were significantly associated with ALT levels 40U/L and above, AST levels between 30U/L and 39U/L and ALP of $120 \mathrm{U} / \mathrm{L}$ and above. Twenty nine percent individuals among prediabetic and $15 \%$ among diabetics had ALT levels equal to or greater than 40U/L. Thirty four percent prediabetics individuals had AST levels between 30U/L and 39U/L and 19\% diabetic individuals had AST levels of greater than 40U/L. Twenty eight percent diabetic individuals had ALP levels of 120U/L and higher (Table 2).

We modeled the odds of abnormal ALT, AST, AST/ALT ratio, ALP, GGT and total bilirubin using glycemic levels (pre-diabetic and diabetic) compared to normal glycemic levels (non-diabetic). Prediabetic glycemic levels were associated with close to two times higher odds of elevated ALP (OR: 1.72, 95\% CI: $1.24,2.40, p<0.05)$ and GGT (OR: 1.81 ,
95\% CI: $1.47,2.23, p<0.001)$ and over one and half times higher odds of ALT (OR: 1.45, 95\% CI: 1.31, $1.60, p<0.001)$ and over 1.3 times of higher odds AST (OR: 1.30, 95\% CI: 1.14, 1.49, $p<0.001$ ) and lower odds of total bilirubin (OR: $0.80,95 \%$ CI: 0.69 , $0.92, p<0.05$ ) (Table 3). On the other hand, diabetic glycemic levels were associated with three times higher odds of elevated ALP (OR: 3.20, 95\%CI: $2.37,4.30, p<0.001)$ and GGT (OR: $2.96,95 \%$ CI: $2.44,3.59, p<0.001)$ and close to one and half times higher odds of ALT (OR: 1.37, 95\% CI: 1.18, 1.59, $p<0.001)$ and AST (OR: 1.48, 95\% CI: 1.24, 1.76, $p<0.001$ ) and lower odds of total bilirubin (OR: 0.76, 95\% CI: 0.62, 0.93, $p<0.001$ ) (Table 3).

\section{Association of Glycemic Levels with Sex Based Levels of Abnormal Liver Enzymes}

High glycemic levels were also found significantly associated with sex-based target abnormal values for ALT $\geq 30 \mathrm{U} / \mathrm{L}$ in male and $\geq 25 \mathrm{U} / \mathrm{L}$ in female, $33 \mathrm{U} / \mathrm{L}$ in both male and female for AST and $\geq 65 \mathrm{U} / \mathrm{L}$ in male and $\geq 36 \mathrm{U} / \mathrm{L}$ in female for GGT compared to normal glycemic levels. Thirty-six percent of individuals with prediabetic and $15 \%$ of individuals with diabetic glycemic levels had high ALT, whereas $17 \%$ individuals with diabetic glycemic levels also had high AST levels. A total of $24 \%$ of individuals with diabetic glycemic levels had high GGT levels $(\mathrm{p}<0.001)$ (Table 4).

\section{Predictors of High Glycemic Levels on Regression Analyses \\ We modeled the odds of abnormal ALT $(\geq 30 \mathrm{U} / \mathrm{L}$ for male and $\geq 25 \mathrm{U} / \mathrm{L}$ for female) and AST ( $\geq 33 \mathrm{U} / \mathrm{L}$ for male and female both), AST/ALT ratio $(\geq 1)$, ALP}


Table 2. Association between diabetes status and liver enzymes.

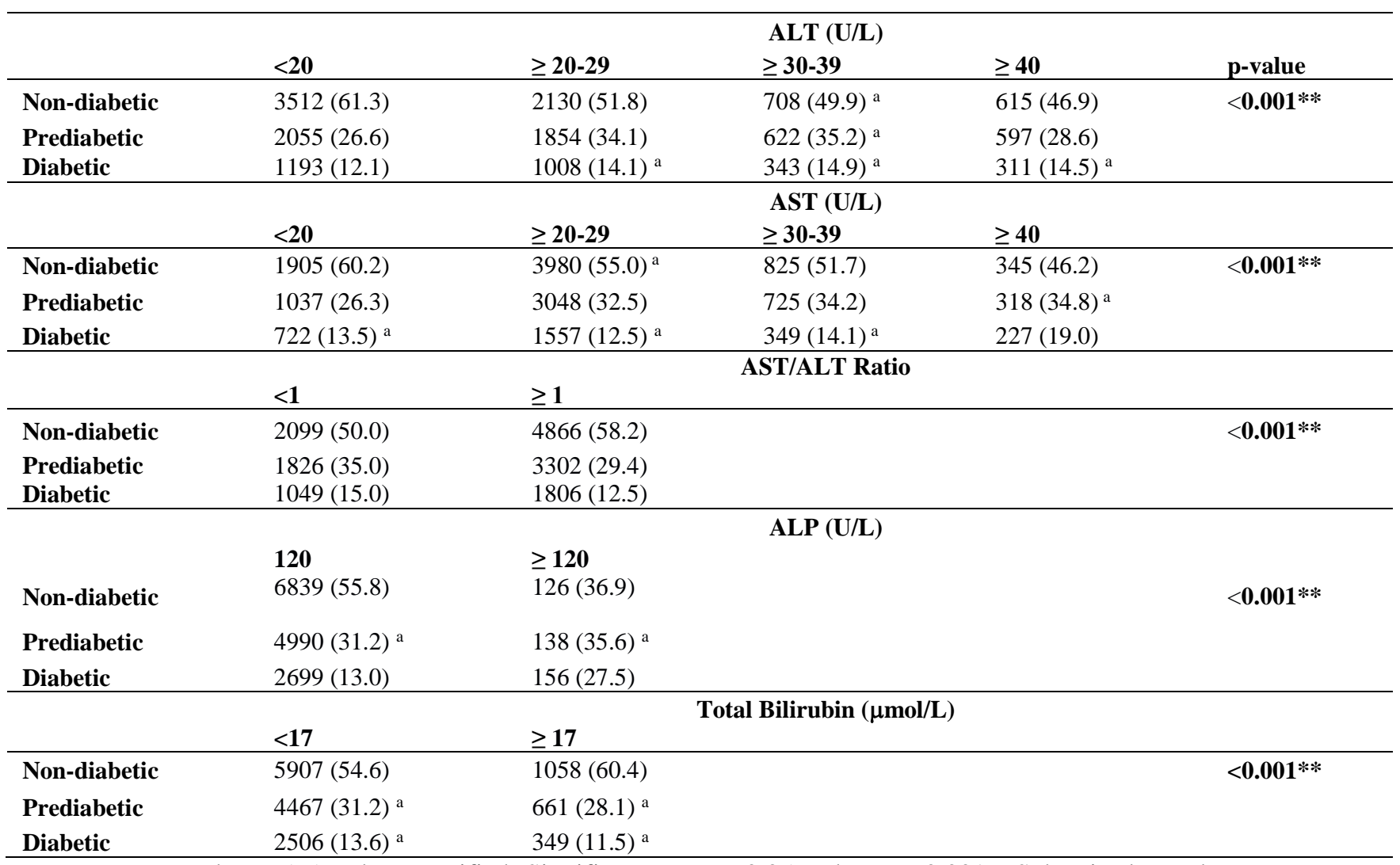

Data were reported as $\mathrm{n}(\%)$ unless specified; Significant at $* p<0.05$ and $* * p<0.001$. ${ }^{\text {a }}$ Subscript letter denotes category whose column proportions did not differ significantly from others on post hoc analyses with Bonferroni correction.

Table 3. Odds of elevated liver enzymes with pre-diabetic and diabetes status.

\begin{tabular}{|c|c|c|c|c|c|c|}
\hline \multirow[t]{2}{*}{ *Diabetes Status } & \multicolumn{2}{|c|}{ ALT (U/L) } & \multicolumn{2}{|c|}{ AST (U/L) } & \multicolumn{2}{|c|}{ AST/ALT Ratio } \\
\hline & OR $(95 \% \mathrm{CI})$ & p-value & OR $(95 \% \mathrm{CI})$ & p-value & OR $(95 \% \mathrm{CI})$ & p-value \\
\hline Pre-diabetic & $1.45(1.31,1.60)$ & $<0.001 * *$ & $1.30(1.14,1.49)$ & $<0.001 * *$ & $0.72(0.65,0.80)$ & $<0.001 * *$ \\
\hline Diabetic & $1.37(1.18,1.59)$ & $<0.001 * *$ & $1.48(1.24,1.76)$ & $<0.001 * *$ & $0.71(0.61,0.83)$ & $<0.001 * *$ \\
\hline \multirow[t]{2}{*}{ *Diabetes Status } & \multicolumn{2}{|c|}{$\operatorname{ALP}(\mathbf{U} / \mathbf{L})$} & \multicolumn{2}{|c|}{ GGT (U/L) } & \multicolumn{2}{|c|}{ Total Bilirubin $(\mu \mathrm{mol} / \mathrm{L})$} \\
\hline & OR $(95 \% \mathrm{CI})$ & p-value & OR $(95 \% \mathrm{CI})$ & p-value & OR $(95 \% \mathrm{CI})$ & p-value \\
\hline Pre-diabetic & $1.72(1.24,2.40)$ & $<0.05^{*}$ & $1.81(1.47,2.23)$ & $<0.001 * *$ & $0.80(0.69,0.92)$ & $<0.05^{*}$ \\
\hline Diabetic & $3.20(2.37,4.30)$ & $<0.001 * *$ & $2.96(2.44,3.59)$ & $<0.001 * *$ & $0.76(0.62,0.93)$ & $<0.001 * *$ \\
\hline
\end{tabular}

$*$ Compared with non-diabetic individuals; OR = Odds Ratio; CI = Confidence Interval; Significant at $* p<0.05$ and $* * p<$ 0.001 .

$(\geq 120 \mathrm{U} / \mathrm{L})$, GGT $(\geq 65 \mathrm{IU} / \mathrm{L}$ for male, $\geq 36 \mathrm{IU} / \mathrm{L}$ for female) and total bilirubin $(\geq 17 \mathrm{mmol} / \mathrm{dl})$ using diabetes status and other covariates simultaneously and calculated the odds ratio using logistic regression model (Table 5). Although included in the model, covariates with non-significant association with liver enzymes were not reported. The overall model was significant for all the liver enzymes accounting for 1.3 to 18 percent of variances and all the liver enzymes were a good fit with $\mathrm{p}$-values of $>0.05$ with the exception of ALT. On regression analysis, after adjustment, pre-diabetic and diabetic status was associated with high ALT (OR:1.21, 95\%CI: 1.11, 1.32, p<0.001), AST (OR:1.14, 95\%CI: 1.04, 1.27, $\mathrm{p}<0.05)$, ALP (OR:1.40, 95\%CI: 1.16, 1.68, $\mathrm{p}<0.001)$ and GGT (OR:1.42, 95\%CI: 1.24, 1.63, $\mathrm{p}<0.001)$. Obesity was associated with high ALT (OR:1.72, 95\%CI: 1.60, 1.85, p<0.001), AST (OR:1.21, 95\%CI: 1.10, 1.33, p<0.001), ALP (OR:1.27, 95\%CI: 1.06, 1.52, $\mathrm{p}<0.05)$ and GGT 
(OR:1.43, 95\%CI: $1.32, \quad 1.55, \quad \mathrm{p}<0.001)$. Hypertension was associated with high ALT (OR:1.19, 95\%CI: 1.04, 1.37, $\mathrm{p}<0.05), \quad$ AST (OR:1.29, 95\% CI: 1.09, 1.53, p<0.05), ALP (OR:1.37, 95\%CI: 1.03, 1.83, p<0.05) and GGT (OR:1.45, 95\%CI: $1.21,1.75$, p<0.001). Female sex was associated with high ALP (OR:1.42, 95\%CI: $1.06,1.90, \mathrm{p}<0.05)$, GGT (OR:1.76, 95\%CI: 1.46, 2.12, $\mathrm{p}<0.001)$ and age with high ALP (OR:1.01, 95\% CI: $1.00,1.02, \mathrm{p}<0.05)$. Female sex was associated with low ALT (OR:0.36, 95\%CI: 0.28, $0.37, \mathrm{p}<0.001$ ), AST (OR: 0.40, 95\%CI: 0.36, 0.46, $\mathrm{p}<0.001$ ) and total bilirubin (OR: 0.33, 95\%CI: 0.28 , $0.37, \mathrm{p}<0.001)$. Non-Hispanic Black race/ethnicity was associated with low ALT (OR:0.99, 95\%CI: 0.94, 1.06, p<0.001), AST (OR: 0.93, 95\%CI: 0.87, 0.97, $\mathrm{p}<0.002$ ), and ALP (OR: 0.81, 95\%CI: 0.73, $0.90, \mathrm{p}<0.001)$ (Table 5). When the model adjusted for $\mathrm{HbA1C}$, FPG and OGTT levels, HbA1C was found to be associated with lower total bilirubin, FPG with high GGT and OGTT with high ALT, AST, ALP, GGT and total bilirubin levels (Supplemental Table S1a).

\section{DISCUSSION}

In the current study, we analyzed adults that are 20 years and older with no history of infection with hepatitis A, B, C, and D. The individuals that participated in NHANES during 2007 to 2016 with glycemic marker data were included in this study. The primary goal of this work is to decipher the association between glycemic markers and liver function through AST, ALT, and ALP in 14,948 adults. As a secondary outcome of the study, we also identified the predictors of liver enzymes in the study population. FPG, OGTT, and HbA1c were associated with the diabetic status of the individuals. Approximately half of the participants were between the age of 20 and 44 years with a mean age of 45.5 years for the study population. About one fifth of the study population had glycemic markers over the diabetic range and $34 \%$ were in the prediabetic domain. However, $47 \%$ of the participants were on antidiabetic medications which suggests that those individuals are susceptible to elevated blood glucose situations. Our analyses indicate that individuals $\geq 45$ years age, female sex, and ethnicity (African American and non-Hispanic white) are associated with hyperglycemia. In agreement with the current dogma, participants that are overweight, hypertensive, and undergo moderate physical activities are prone to develop hyperglycemic conditions.

The mean of glycemic markers (FPG, OGTT, and $\mathrm{HbA1c}$ ) in the diabetic group was $149.3 \mathrm{mg} / \mathrm{dl}$, $227.7 \mathrm{mg} / \mathrm{dL}$, and $7.2 \%$, respectively. We have found that AST $\geq 33 \mathrm{U} / \mathrm{L}$ and ALP $\geq 120 \mathrm{U} / \mathrm{L}$ are significantly associated with high glycemic levels in diabetic individuals. Similarly, prediabetic glycemic levels were associated with AST 30-39 U/L and ALP $\geq 120 \mathrm{U} / \mathrm{L}$. Though liver function is one of the most commonly measured laboratory markers, the upper limit of normal varies from different guidelines. For ALT, values as low as $>18 \mathrm{U} / \mathrm{L}$ in females and $>29$ in males are considered abnormal range (14). Likewise, AST of $>33$ both in male and female can be considered elevated liver function (15). In general, AST or ALT of $\geq 40 \mathrm{U} / \mathrm{L}$ and ALP $\geq 120 \mathrm{U} / \mathrm{L}$ are used more frequently for the upper limit of normal. In the present study, a significant proportion of the study participants had levels $\geq 40 \mathrm{U} / \mathrm{L}$ of AST or $\geq 120 \mathrm{U} / \mathrm{L}$. From the odds ratio analyses, we infer those diabetic participants had three times higher odds of elevated ALP and GGT, and about one and half times odds of increased AST and ALT. For the same parameters, prediabetic participants also had odds ratio in the range of 1.30 to 1.81 . In addition, hyperglycemic levels of participants were significantly associated with sex-based cut-off values of abnormal liver enzyme functions.

Previous independent studies with populations from different countries (e.g., United States, Taiwan, India, China) have reported the relationship of type 2 diabetes and liver health status. Jeon et al. (2013) reported that individuals that are not aware of their hyperglycemic conditions have a higher probability of increased ALT and AST levels. Interestingly, the study did not find any relationship between the use of antidiabetic medications (sulfonylureas, biguanides/thiazolidinediones) and liver injury in the NHANES population between 1999 to 2008. The cross-sectional nature of the NHANES data and its related confounding factors compared to randomized clinical studies has been assigned to this lack of association (16). A different study with adolescent population of 12-19 years (NHANES 1999-2004) describes that higher ALT levels are associated with fasting insulin levels and C-reactive protein levels. About $8 \%$ of the adolescent study individuals had higher ALT levels. The occurrences of increased ALT levels were sex, ethnicity (African American, Mexican American, White American), and socioeconomic status dependent (17). In another cross-sectional study with NHANES population 
Table 4. Association between diabetes status and liver enzymes (sex-based cut-off value).

\begin{tabular}{|c|c|c|c|}
\hline & \multicolumn{3}{|c|}{$\operatorname{ALT}(\mathbf{U} / \mathbf{L})$} \\
\hline & $<30 \mathrm{U} / \mathrm{L}(\mathrm{M}) \&<25 \mathrm{U} / \mathrm{L}(\mathrm{F})$ & $\geq 30 \mathrm{U} / \mathrm{L}(\mathrm{M}) \& \geq 25 \mathrm{U} / \mathrm{L}(\mathrm{F})$ & p-value \\
\hline Non-diabetic & $5334(57.7)$ & $1631(48.9)$ & $<0.001 * *$ \\
\hline Prediabetic & $3633(29.5)$ & $1495(36.2)$ & \\
\hline \multirow[t]{3}{*}{ Diabetic } & $2051(12.8)$ & $804(14.9)$ & \\
\hline & \multicolumn{3}{|c|}{$\operatorname{AST}(\mathbf{U} / \mathbf{L})$} \\
\hline & $<33 \mathrm{U} / \mathrm{L}(\mathrm{M} \& \mathrm{~F})$ both & $\geq 33 \mathrm{U} / \mathrm{L}(\mathrm{M} \& \mathrm{~F})$ both & \\
\hline Non-diabetic & $6186(56.3)$ & $779(48.8)$ & $<0.001 * *$ \\
\hline Prediabetic & $4439(30.8)^{\mathrm{a}}$ & $689(34.7)^{\mathrm{a}}$ & \\
\hline \multirow[t]{3}{*}{ Diabetic } & $2438(12.9)$ & $417(16.5)$ & \\
\hline & \multicolumn{3}{|c|}{ GGT $(\mathbf{U} / \mathbf{L})$} \\
\hline & $<65 \mathrm{U} / \mathrm{L}(\mathrm{M}) \&<36 \mathrm{U} / \mathrm{L}(\mathrm{F})$ & $\geq 65 \mathrm{U} / \mathrm{L}(\mathrm{M}) \& \geq 36 \mathrm{U} / \mathrm{L}(\mathrm{F})$ & \\
\hline Non-diabetic & $6493(56.9)$ & $472(38.2)$ & $<0.001 * *$ \\
\hline Prediabetic & $4608(30.8)^{a}$ & $520(37.3)^{a}$ & \\
\hline Diabetic & $2405(12.3)$ & $450(24.4)$ & \\
\hline
\end{tabular}

Data were reported as $\mathrm{n}(\%)$ unless specified; Significant at $* p<0.05$ and $* * p<0.001$. a Subscript letter denotes category whose column proportions did not differ significantly from others on post hoc analyses with Bonferroni correction.

(2005-2016) 78\% of the type 2 diabetes patients was diagnosed with NAFLD (mean age: $57.9 \pm 0.4$ years). Common liver function markers such as AST, ALT, and GGT were higher $(\mathrm{P}<0.001)$ in the NAFLD individuals than the non-NAFLD group. Significantly higher BMI, waist circumferences, and platelet count are other key parameters that were higher in the NAFLD group (18). Ciardullo et al. (2021) have shown that $8.1 \%$ and $17.9 \%$ patients from a pool of 825 patients were cognizant of their steatosis and fibrosis liver conditions, respectively (19). In extreme and chronic situations, it is possible that relatively older individuals (mean age: $60.59 \pm$ 11.29 years) can develop hepatocellular carcinoma as outlined in the National cohort of Taiwan Diabetes Study. The HbA1c of $\geq 9 \%$ is strongly associated with hepatocellular carcinoma and could be an indicator of progressive cancer risk (20). In a retrospective study with 320 diabetic patients from Northeast India, $71.25 \%$ of the participants had at least one of the liver parameters elevated than the normal range. The sex-specific differences in increased ALT and increased ALP levels were most prevalent in males and females, respectively (21). Similarly, a cross-sectional study with 1,198 diabetic individuals in China has shown that about $10.3 \%$ and $6.1 \%$ participants had increased ALT and AST levels, respectively. Patients on antihyperglycemic medications demonstrated lower AST and ALT levels (22).

The underlying mechanism of liver dysfunction from hyperglycemic conditions could be explained through physiological perspectives. Liver dysfunction can occur as a result of both histological as well as biochemical changes. The rough endoplasmic reticulum is remarkably diminished as a consequence of elevated sugar levels (23). Similarly, lower number of mitochondrial cristae and altered nuclear membranes in hyperglycemia may contribute to the abnormal liver function $(24,25)$. From a biochemical perspective, diabetes and liver function appear to be a vicious cycle where the hyperglycemia in type 2 diabetes can cause liver dysfunction and in turn liver dysfunction can further aggravate the insulin resistance and hepatic glucose metabolism issues. Elevated blood sugar levels can create glucotoxicity and in parallel initiate lipogenesis and lipotoxicity. Combination of glucotoxicity and lipotoxicity triggers inflammatory pathways and release cytokines such as interleukins and tumor necrosis factor. Indeed, Svensson et al. (2014) have reported that CRP levels were significantly elevated in the type 2 diabetes patients (26). Subsequently, these inflammatory proteins promote the formation of reactive oxygen species and cause oxidative stress. These cascades of events can potentially lead to hepatocyte death and decreased liver cell capacity which can eventually orchestrate the increase in liver function tests. Elevation in liver enzyme functions could be a mechanism to compensate the decreased number of liver cells as shown in Figure 1. On the other hand, compromised liver function status does not afford the liver to sense the presence of glucose and forms 
Table 5. Predictors of liver enzymes on regression (adjusted model).

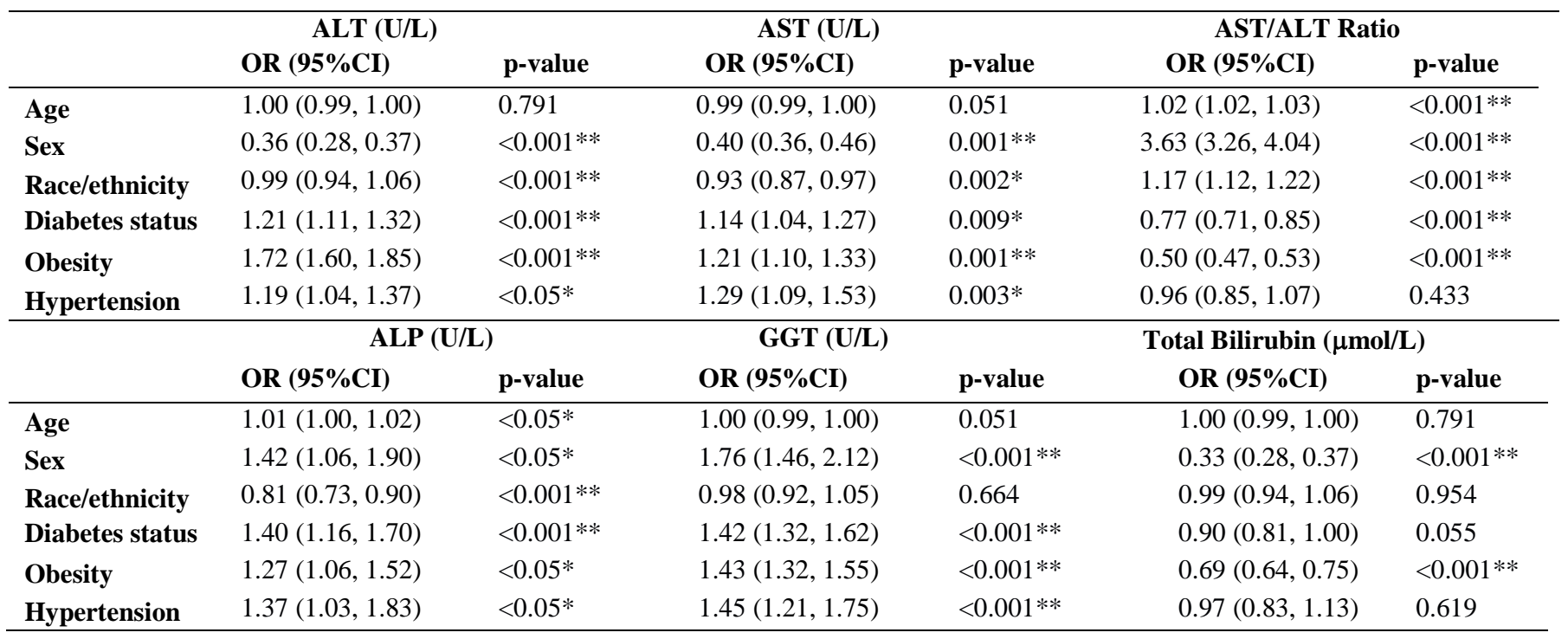

\section{Hyperglycemia}

\section{Glucotoxicity}

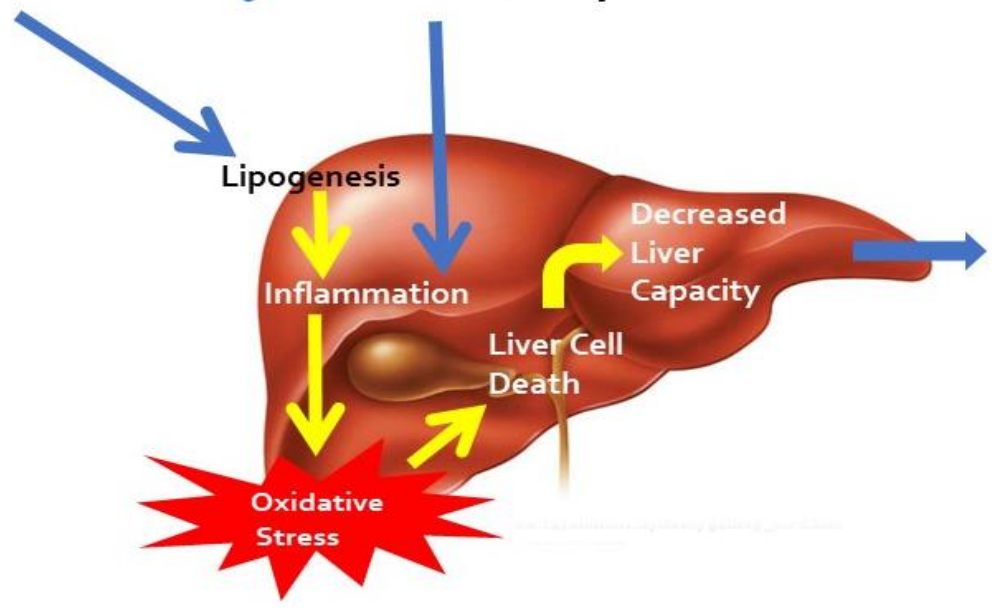

\section{$\uparrow \mathrm{ALT}, \uparrow \mathrm{AST}, \uparrow \mathrm{ALP}$ (To compensate decreased number of liver cells)}

Figure 1: Potential mechanism of hyperglycemia-related liver dysfunction.

excess amount of glucose, leading to continued damage to the liver $(27,28)$. It has been recognized that treatment of hyperglycemia with antidiabetic drugs such as glucagon like peptide-1 receptor agonists, dipeptidyl peptidase-4 inhibitors, and insulin sensitizers (e.g., metformin, pioglitazone) could be the investigational agents for diabetesrelated nonalcoholic steatohepatitis (NASH) and NAFLD (29).

Overall, results from our study indicate towards hepatic dysfunction in individuals with diabetes. The findings in general are agreement with the past studies, albeit from a different time period and/or population, that chronic elevation of glucose levels can cause liver injury. Our study is somewhat different than the other cross-sectional studies in terms of the mean age of the study population where the current study has the mean age of 45.5 years compared to $>57$ years or the adolescent individuals. Though, unlike some of the previous studies, our study individuals were not segregated based their use of antidiabetic medications, the glycemic index and liver function recorded may also be a reflection of blood sugar lowering effects of those mediations. Our study had several limitations. First, we could not examine the longitudinal effect of hyperglycemia and hepatic function as a result of cross-sectional study design. Prospective studies with repeated measure of hepatic function could be more informative as hepatic function is subject to temporal 
variation especially in the presence of comorbidities. Secondly, we used an indirect assessment of liver dysfunction or liver diseases by relying on ALT and AST as a surrogate marker and only a single measurement of ALT and AST levels was available for each individual in the NHANES data. Third, despite the large dataset, the proportions of people with low HbA1c, high ALT and AST were comparatively small. Therefore, the power can be limited in these categories only. Fourth, we excluded the data on alcohol intake, since it was limited for the sample population selected, moreover, the amount of alcohol intake varied greatly among individuals representing heterogeneity. Lastly, our findings are based on the variables available in the dataset and the observed findings could be attributed to unknown confounding.

Regardless of the limitations, our study has several strengths. We used a dataset which is a representative of non-institutionalized adult population in the U.S. thus making our findings generalizable to the US adult population living with diabetes. We have also considered potential confounders relevant to hepatic health including hepatitis B and C infection. Furthermore, we were able to identify and categorized individuals with undiagnosed diabetes using data on fasting blood glucose and glycohemoglobin collected as a part of NHANES.

\section{CONCLUSIONS}

In summary, routinely measured glycemic biomarkers such as FPG, OGTT, and HbA1c are significantly associated with liver enzyme functions among adults in the United States. These findings deserve further exploration to discern the longitudinal effect of diabetes on liver function. It is likely that diabetes could be a predictor of liver health in the adults from United States.

CONFLICT OF INTEREST. Authors have no financial or any other conflict of interest to declare.

\section{REFERENCES}

1. Centers for Disease Control and Prevention. National Diabetes Statistics Report, 2020. Available from: https://www.cdc.gov/diabetes/data/statisticsreport/index.html. Accessed February 25, 2021.
2. World Health Organization. Diabetes on the rise. Available from: https://www.who.int/diabetes/globalreport/WHD2016_Diabetes_Infographic_v2.p df?ua=1. Accessed February 25, 2021.

3. Papatheodorou K, Banach M, Bekiari E, Rizzo M, Edmonds M. Complications of Diabetes 2017. J Diabetes Res. 2018;2018:3086167. Epub 2018/05/02. doi:10.1155/2018/3086167. Cited in: Pubmed; PMID 29713648.

4. American Diabetes Association. Statistics About Diabetes. 2018 Feb 25, 2021. Available from:

https://www.diabetes.org/resources/statistics/ statistics-about-diabetes. Accessed February 25, 2021.

5. Triplitt CL. Examining the mechanisms of glucose regulation. Am J Manag Care. 2012 Jan;18(1 Suppl):S4-10. Epub 2012/05/18. Cited in: Pubmed; PMID 22559855.

6. American Diabetes Association. 6. Glycemic Targets: Standards of Medical Care in Diabetes-2021. Diabetes Care. 2021 Jan;44(Suppl 1):S73-S84. Epub 2020/12/11. doi:10.2337/dc21-S006. Cited in: Pubmed; PMID 33298417.

7. American Diabetes Association. 2. Classification and Diagnosis of Diabetes: Standards of Medical Care in Diabetes-2019. Diabetes Care. 2019 Jan;42(Suppl 1):S13-S28. Epub 2018/12/19. doi:10.2337/dc19-S002. Cited in: Pubmed; PMID 30559228.

8. Contreras-Zentella ML, Hernandez-Munoz R. Is Liver Enzyme Release Really Associated with Cell Necrosis Induced by Oxidant Stress? Oxid Med Cell Longev. 2016;2016:3529149. Epub 2016/01/23. doi:10.1155/2016/3529149. Cited in: Pubmed; PMID 26798419.

9. Malhi H, Gores GJ. Cellular and molecular mechanisms of liver injury. Gastroenterology. 2008 May;134(6):1641-54. Epub 2008/05/13. doi:10.1053/j.gastro.2008.03.002. Cited in: Pubmed; PMID 18471544.

10. National Health and Nutrition Examination Survey (NHANES), National Center for Health Statistics. Hyattsville, MD; Center for Disease Control and Prevention, U.S. Department of Health and Human Services, $2017 . \quad$ Available from: https://wwwn.cdc.gov/nchs/nhanes/analyticgu idelines.aspx. Accessed February 25, 2021.

11. The Practical Guide Identification, Evaluation, and Treatment of Overweight and Obesity in 
Adults, NHLBI Obesity Education Initiative, National Institute of Health, https://www.nhlbi.nih.gov/files/docs/guidelin es/prctgd_c.pdf, 2017.

12. STATA 14; StataCorp, Stata Statistical Software: Release 13, College Station, TX: StataCorp LP. 2013.

13. Aragon G, Younossi ZM. When and how to evaluate mildly elevated liver enzymes in apparently healthy patients. Cleve Clin J Med. 2010 Mar;77(3):195-204. Epub 2010/03/05. doi:10.3949/ccjm.77a.09064. Cited in: Pubmed; PMID 20200170.

14. Newsome PN, Cramb R, Davison SM, Dillon $\mathrm{JF}$, Foulerton M, Godfrey EM, Hall R, Harrower U, Hudson M, Langford A, Mackie A, Mitchell-Thain R, Sennett K, Sheron NC, Verne J, Walmsley M, Yeoman A. Guidelines on the management of abnormal liver blood tests. Gut. 2018 Jan;67(1):6-19. Epub 2017/11/11. doi:10.1136/gutjnl-2017-314924. Cited in: Pubmed; PMID 29122851.

15. Xiao Q, Sinha R, Graubard BI, Freedman ND. Inverse associations of total and decaffeinated coffee with liver enzyme levels in National Health and Nutrition Examination Survey 1999-2010. Hepatology. 2014 Dec;60(6):2091-8. Epub 2014/08/16. doi:10.1002/hep.27367. Cited in: Pubmed; PMID 25124935.

16. Jeon CY, Roberts CK, Crespi CM, Zhang ZF. Elevated liver enzymes in individuals with undiagnosed diabetes in the U.S. J Diabetes Complications. 2013 Jul-Aug;27(4):333-9. Epub 2013/05/21 doi:10.1016/j.jdiacomp.2013.04.005. Cited in: Pubmed; PMID 23683663.

17. Fraser A, Longnecker MP, Lawlor DA. Prevalence of elevated alanine aminotransferase among US adolescents and associated factors: NHANES 1999-2004. Gastroenterology. 2007 Dec;133(6):1814-20. Epub 2007/12/07. doi:10.1053/j.gastro.2007.08.077. Cited in: Pubmed; PMID 18054554.

18. Ciardullo S, Sala I, Perseghin G. Screening strategies for nonalcoholic fatty liver disease in type 2 diabetes: Insights from NHANES 2005-2016. Diabetes Res Clin Pract. 2020 Sep;167:108358. Epub 2020/08/04. doi:10.1016/j.diabres.2020.108358. Cited in: Pubmed; PMID 32745698.
19. Ciardullo S, Monti T, Perseghin G. Lack of awareness of liver organ damage in patients with type 2 diabetes. Acta Diabetol. 2021 Jan 26. Epub 2021/01/27. doi:10.1007/s00592021-01677-y. Cited in: Pubmed; PMID 33496855.

20. Li CI, Chen HJ, Lai HC, Liu CS, Lin WY, Li TC, Lin CC. Hyperglycemia and chronic liver diseases on risk of hepatocellular carcinoma in Chinese patients with type 2 diabetes-National cohort of Taiwan Diabetes Study. Int J Cancer. 2015 Jun 1;136(11):2668-79. Epub 2014/11/13. doi:10.1002/ijc.29321. Cited in: Pubmed; PMID 25387451.

21. Bora K, Borah M, Chutia H, Nath CK, Das D, Ruram AA. Presence of Concurrent Derangements of Liver Function Tests in Type 2 Diabetes and Their Relationship with Glycemic Status: A Retrospective Observational Study from Meghalaya. J Lab Physicians. 2016 Jan-Jun;8(1):30-5. Epub 2016/03/26. doi:10.4103/0974-2727.176227. Cited in: Pubmed; PMID 27013810.

22. Chen S, Guo X, Chen Y, Dong S, Sun Y. Prevalence of abnormal serum liver enzymes in patients with type 2 diabetes mellitus: a cross-sectional study from China. Postgrad Med. 2016 Nov;128(8):770-776. Epub 2016/10/18.

doi:10.1080/00325481.2016.1242366. Cited in: Pubmed; PMID 27681272.

23. Palsamy P, Sivakumar S, Subramanian S. Resveratrol attenuates hyperglycemiamediated oxidative stress, proinflammatory cytokines and protects hepatocytes ultrastructure in streptozotocin-nicotinamideinduced experimental diabetic rats. Chem Biol Interact. 2010 Jul 30;186(2):200-10. Epub 2010/03/24. doi:10.1016/j.cbi.2010.03.028. Cited in: Pubmed; PMID 20307516.

24. Lucchesi AN, Cassettari LL, Spadella CT. Alloxan-induced diabetes causes morphological and ultrastructural changes in rat liver that resemble the natural history of chronic fatty liver disease in humans. J Diabetes Res. 2015;2015:494578. Epub 2015/03/20. doi:10.1155/2015/494578. Cited in: Pubmed; PMID 25789328.

25. Welt K, Weiss J, Martin R, Dettmer D, Hermsdorf T, Asayama K, Meister S, Fitzl G. Ultrastructural, immunohistochemical and biochemical investigations of the rat liver exposed to experimental diabetes und acute 
hypoxia with and without application of Ginkgo extract. Exp Toxicol Pathol. 2004 Mar;55(5):331-45. Epub 2004/04/20. doi:10.1078/0940-2993-00337. Cited in: Pubmed; PMID 15088635.

26. Svensson E, Mor A, Rungby J, Berencsi K, Nielsen JS, Stidsen JV, Friborg S, Brandslund I, Christiansen JS, Beck-Nielsen H, Sorensen HT, Thomsen RW. Lifestyle and clinical factors associated with elevated C-reactive protein among newly diagnosed Type 2 diabetes mellitus patients: a cross-sectional study from the nationwide DD2 cohort. BMC Endocr Disord. 2014 Aug 28;14:74. Epub 2014/08/29. doi:10.1186/1472-6823-14-74. Cited in: Pubmed; PMID 25163828.

27. Reid AE. Non-alcoholic fatty liver disease. In: Feldman M, Friedman LS, Brandt LJ, Eds.
Sleisenger and Fordtran's Gastrointestinal and Liver Disease: Pathophysiology/diagnosis/ management, 8th ed. St. Louis, Missouri, USA: Saunders, 2006. Pp. 1772-99.

28. Crawford JM, Iacobuzio-Donahue C. Liver and biliary tract. In: Kumar V, Abbas AK, Fausto N, Aster JC, Eds. Robbins and Cotran Pathologic Basis of Disease. 8th ed. Philadelphia, Pennsylvania, USA: Saunders, 2009. Pp. 833-90.

29. Gastaldelli A, Cusi K. From NASH to diabetes and from diabetes to NASH: Mechanisms and treatment options. JHEP Rep. 2019 Oct;1(4):312-328. Epub 2020/02/11. doi:10.1016/j.jhepr.2019.07.002. Cited in: Pubmed; PMID 32039382.

Supplemental Table S1a. Predictors of liver enzymes on regression (adjusted model)

\begin{tabular}{|c|c|c|c|c|c|c|}
\hline & \multicolumn{2}{|c|}{ ALT (U/L) } & \multicolumn{2}{|l|}{ AST (U/L) } & \multicolumn{2}{|c|}{ AST/ALT Ratio } \\
\hline & OR $(95 \% \mathrm{CI})$ & p-value & OR $(95 \% \mathrm{CI})$ & p-value & OR $(95 \% \mathrm{CI})$ & p-value \\
\hline Age & $0.99(0.98,0.99)$ & $<0.001 * *$ & $0.99(0.99,1.00)$ & 0.601 & $1.02(1.02,1.03)$ & $<0.001 * *$ \\
\hline Sex & $0.44(0.37,0.53)$ & $<0.001 * *$ & $0.38(0.30,0.50)$ & $<0.001 * *$ & $3.42(2.84,4.12)$ & $<0.001 * *$ \\
\hline Race/ethnicity & $0.80(0.74,0.85)$ & $<0.001 * *$ & $0.86(0.79,0.94)$ & $<0.001 * *$ & $1.25(1.17,1.33)$ & $<0.001 *$ \\
\hline HbA1C & $1.04(0.82,1.32)$ & 0.745 & $1.00(0.72,1.40)$ & 0.975 & $0.89(0.70,1.12)$ & 0.319 \\
\hline FPG & $1.00(0.99,1.01)$ & 0.194 & $0.99(0.98,1.00)$ & 0.424 & $0.99(0.98,1.00)$ & 0.066 \\
\hline \multirow[t]{3}{*}{ OGTT } & $1.01(1.00,1.02)$ & $<0.001 * *$ & $1.00(1.00,1.00)$ & $<0.05^{*}$ & $0.99(0.99,0.99)$ & $<0.001 * *$ \\
\hline & \multicolumn{2}{|c|}{$\operatorname{ALP}(\mathbf{U} / \mathbf{L})$} & \multicolumn{2}{|l|}{ GGT (U/L) } & \multicolumn{2}{|c|}{ Total Bilirubin $(\mu \mathrm{mol} / \mathrm{L})$} \\
\hline & OR $(95 \% \mathrm{CI})$ & p-value & OR $(95 \% \mathrm{CI})$ & p-value & OR $(95 \% \mathrm{CI})$ & p-value \\
\hline Age & $1.01(1.00,1.02)$ & $<0.05^{*}$ & $1.001(1.00,1.02)$ & $<0.05^{*}$ & $1.007(1.00,1.01)$ & $<0.05^{*}$ \\
\hline Sex & $1.17(0.65,2.08)$ & 0.597 & $1.83(1.30,2.58)$ & $<0.001 * *$ & $0.35(0.29,0.44)$ & $<0.001^{* *}$ \\
\hline Race/ethnicity & $0.80(0.64,0.99)$ & $<0.05^{*}$ & $0.92(0.83,1.01)$ & 0.085 & $1.06(0.99,1.13)$ & 0.075 \\
\hline HbA1C & $1.10(0.66,1.85)$ & 0.703 & $0.78(0.52,1.16)$ & 0.212 & $0.36(0.27,0.48)$ & $<0.001 *$ \\
\hline FPG & $0.99(0.98,1.00)$ & 0.414 & $1.01(1.00,1.02)$ & $<0.001 * *$ & $0.99(0.99,1.01)$ & 0.888 \\
\hline OGTT & $1.01(1.00,1.01)$ & $<0.001 * *$ & $1.01(1.00,1.02)$ & $<0.001 * *$ & $1.01(1.00,1.02)$ & $<0.05^{*}$ \\
\hline
\end{tabular}

OR = Odds Ratio; CI = Confidence Interval; HbA1C: Glycosylated hemoglobin; FPG: Fasting Plasma Glucose; OGTT: Oral Glucose Tolerance Test; Significant at $* p<0.05$ and $* * p<0.001$. 